\title{
IMPLEMENTASI PELAKSANAAN MANAJEMEN BENGKEL BERBASIS 5-S DI BENGKEL MESIN OTOMOTIF POLITEKNIK NEGERI TANAH LAUT
}

\author{
Adhiela Noer Syaief \\ Program Studi Mesin Otomotif Politeknik Negeri Tanah Laut \\ Email : adhel_syaief@politala.ac.id
}

\begin{abstract}
Abstrak
Bengkel Mesin Otomotif Politeknik Negeri Tanah Laut merupakan salah satu sarana penunjang proses belajar khususnya praktek yang ada dilingkungan kampus Politeknik Negeri Tanah Laut. Adapun tujuan dari penelitian ini adalah untuk mengetahui pelaksanaan manajemen bengkel mesin otomotif yang berbasis Seiri, Seiton, Seiso, Seiketsu, Shitsuke. Penelitian ini menggunakan pendekatan kualitatif. Proses peng-umpulan data menggunakan wawancara, dokumentasi, dan observasi. Objek penelitian ini adalah bengkel mesin otomotif Politeknik Negeri Tanah Laut, laboran, teknisi dan dosen pembimbing praktek. Teknik analisis data yang digunakan dalam penelitian ini adalah reduksi data, display data, dan penarikan kesimpulan. Untuk mengecek keabsahan data dilakukan dengan melakukan pengamatan ulang dan melakukan triangulasi. Hasil Penelitian menunjukan bahwa pelaksanaan manajemen bengkel berbasis 5-S (seiri, seiton, seiso, seiketsu, shitsuke) di bengkel mesin otomotif Politeknik Negeri Tanah laut sudah berjalan dengan baik.
\end{abstract}

Kata Kunci: manajemen bengkel, 5-S, bengkel mesin otomotif

\section{LATAR BELAKANG}

Layaknya sebuah industri, politeknik sebagai sebuah lembaga penyelenggara pendidikan. Yang mana menghasilkan suatu produk tertentu dengan senatiasa menjaga kualitas, pengolahan bahan baku atau proses produksi yang dilakukan dikampus melalui sebuah proses belajar mengajar. Guna menunjang ini semua, tentunya diperlukan dengan kelengkapan dan kualitas laboratorium ataupun bengkel yang sesuai dengan standart.

Bengkel mesin otomotif Politeknik Negeri Tanah Laut sudah memiliki fasilitas praktikum yang memadai yang mana fasilitas ini terus menerus akan ditingkatkan kualitas dan kuantitasnya.

Laboratorium atau bengkel pada politeknik merupakan sarana yang sangat penting, karena bengkel merupakan sarana yang memberikan ciri khusus pada pendidikan yang ada di politeknik dengan komposisi $70 \%$ praktek dan $30 \%$ teori. Pengelolaan sebuah bengkel meliputi bagaimana sistem penataan dan perawatannya. Sehingga bengkel dapat digunakan mahasiswa secara optimal untuk menunjang proses belajar mengajar.

Tujuan dari perawatan dan penataan bengkel adalah agar dapat digunakan dengan cepat, aman dan nyaman. Sehingga dapat mendukung proses belajar mahasiswa menjadi lebih baik. Saat ini bengkel mesin otomotif belum mempunyai system penataan dan perawatan yang baik dan belum ada kegiatan yang secara khusus memberikan wawasan tentang bagaimana melakukan penataan dan perawatan bengkel.

Aplikasi manajemen bengkel yang ditinjau dari konsep $5 \mathrm{~S}$ (seiri, seiton, seiso, seiketsu, dan shitsuke) bertujuan untuk meningkatkan kualitas bengkel mesin otomotif.

Manajemen suatu perusahaan atau organisasi tidak akan dapat mencapai tujuan yang telah ditetapkan apabila tidak memiliki suatu sistem manajemen yang baik. Walaupun manajemen hanya merupakan alat untuk mencapai tujuan tetapi harus diatur sebaik mungkin. Karena jika manajemen baik maka tujuan optimal dapat diwujudkan, pembo-rosan terhindari, 
dan semua potensi yang dimiliki akan lebih bermanfaat. Hasibuan

(2009:1) menjelaskan bahwa manajemen berasal dari kata to manage yang artinya mengatur. Pengaturan dilakukan melalui proses dan diatur berdasarkan urutan dari fungsi-fungsi manajemen itu.

5-S adalah sebuah cara baru dalam manajemen sebuah bengkel khususnya bengkel sekolah kejuruan. Konsep 5-S berasal dari negara Jepang dan di Indonesia dikenal dengan 5-R. Prinsip 5-S merupakan huruf awal dari lima kata Jepang yaitu: Seiri, Seiton, Seiso, Seiketsu, dan Shitsuke, yang dalam perkembangannya di Indonesia dikenal dengan 5-R yaiu: Ringkas, Rapi, Resik, Rawat, dan Rajin. Kata-kata tersebut mencerminkan urutan penerapan dari proses trans-formasi 5-S (Rimawan dan Sutowo, 2012). 5-S merupakan kebulatan tekad untuk mengadakan penataan, pembersihan, memelihara kondisi yang mantap dan memelihara kebiasaan yang diperlukan untuk melaksanakan pekerjaan dengan baik. Dari definisi di atas dapat disimpulkan bahwa 5-S meru-pakan suatu cara atau langkah dalam upaya menciptakan dan menjaga mutu lingkungan kerja agar terciptanya kondisi kerja yang aman dan nyaman. 5-S terdiri dari Seiru, Seiton, Seiso, Seiketsu, Shitsuke.

Di Indonesia 5-S diterjemahkan menjadi 5 R, yaitu Ringkas, Rapi, Resik, Rawat, Rajin. Penjabaran dari konsep 5S adalah: (1) Seiri (Pemilihan) Aktivitas mengatur segala sesuatu, memilah sesuai dengan aturan dan prinsip tertentu atau dapat dikatakan bahwa pemilihan adalah seni membuang barang. Dalam 5-S ber-arti membedakan antara yang diperlukan dengan yang tidak diperlukan, mengambil keputusan yang tegas dan menerapkan manajemen stratifikasi untuk membuang yang tidak diperlukan, (2) Seiton (penataan) menyimpan barang di tempat yang tepat atau dalam tata letak yang benar dengan mem-perhatikan efisiensi, kualitas dan keamanan serta mencari cara penyimpanan yang opti-mal sehingga dapat digunakan dalam keada-an mendadak karena dapat menghilangkan proses pencarian. Penataan juga termasuk mengambil keputusan tentang berapa ba-nyak yang akan disimpan dan dimana me-nyimpannya. (3) Seiso (pembersihan) seiso berarti membuang kotoran dan benda-benda asing serta membersihkan segala sesuatu. (4) Seiketsu (Pemantapan) pemantapan berarti terusmenerus dan secara berulangulang memelihara pemilihan, penataan dan pem-bersihan. Ini berarti melaksanakan aktivitas $5 \mathrm{~S}$ dengan teratur sehingga keadaan yang tidak normal tampak dan melatih keterampilan untuk menciptakan dan memeli-hara kontrol visual. (5) Shitsuke (pembiasaan) pembiasaan adalah melakukan pekerjaan berulang-ulang sehingga secara alami kita dapat melakukan dengan benar. Jika kita ingin melakukan pekerjaan secara efisien dan tanpa kesalahan maka kita harus melakukan setiap hari. Pada penelitian ini bertujuan untuk mengetahui pelaksanaan manajemen bengkel mesin ditinjau dari seiri, seiton, seisi, seiketsu, shitsuke.

\section{METODE PENELITIAN}

Langkah awal yang harus dilakukan sebelum melakukan penelitian adalah melakukan pengamatan. Pengamatan dilakukan ke bengkel mesin otomotif yang menjadi objek penelitian. Langkah yang dilakukan untuk mengetahui permasalahan yang ada di bengkel.

Langkah selanjutnya yang dilakukan adalah pengumpulan data dengan melakukan wawancara terkait dengan implementasi manajemen berbasis $5-\mathrm{S}$ di bengkel mesin otomotif Politeknik Negeri Tanah Laut.

Teknik analisis data yang digunakan dalam penelitian ini adalah melakukan 
reduksi data, display data kemudian melakukan penarikan kesimpulan. Setelah menganalisis data kemudian pengecekan keabsahan data, peneliti melakukan pengamatan ulang dan melakukan triangulasis yaitu dengan mencocokan hasil wawancara dengan hasil dokumentasi yang diperoleh oleh peneliti di lapangan.

\section{HASIL DAN PEMBAHASAN}

\section{Penerapan 5-S di Bengkel Mesin Otomotif Politeknik Negeri Tanah Laut}

Pada tahap ini akan dijelaskan mengenai pelaksanaan 5S di bengkel mesin otomotif Politeknik Negeri Tanah Laut

\section{Pelaksanaan Seiri}

Pelaksanaan Seiri adalah proses pemilihan dengan memilih mana barang yang di buang atau barang yang masih bisa dipergunakan lagi. Hal-hal yang dilakukan dalam menangani tumpukan barang di bengkel itu yaitu: (1) Melakukan pembersihan secara keseluruhan dan (2) Membuang barang yang tidak diperlukan.

Untuk hasil benda kerja mahasiswa yang rusak akan di tampung dan dipilah lagi ada yang di jual dan ada yang di buat kerajinan. Untuk mesin-mesin yang rusak itu dan yang tidak bisa di pergunakan lagi itu di simpan di gudang bengkel. Proses seiri dapat dilihat dari hasil dokumentasi yang berupa gambar di bawah ini:

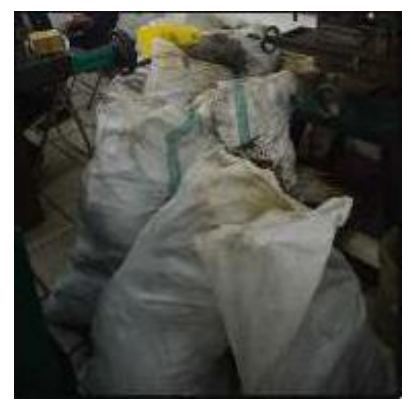

Gambar 1 Pelaksanaan Seiri Tumpukan Sisa bahan praktek

\section{Pelaksanaan Seiton}

Seiton (penataan) di paparkan menjadi empat yaitu penataan alat, pengolahan data base, pengelolahan material praktik mahasiswa, dan pengelolahan hasil praktik mahasiswa.

\section{a. Penataan Alat}

Pinsip dasar seiton adalah melakukan pengaturan lingkungan kerja dan peralatan secara rapi dengan sasaran tata letak dan pe-nempatan yang efisien sehingga pemborosan waktu untuk mencari barang bisa dihilang-kan, untuk memper-lancar pekerjaan. Semua alat di bengkel mesin otomotif Politeknik Negeri Tanah Laut sudah ditata rapi sesuai dengan kemiripan, ukuran, dan karakteristik pernyataan diatas didukung dengan teroi dari Hadiguna dan Setiawan (2008) memaparkan bahwa dalam menata alat agar tertata rapi harus ditata sesuai dengan kemiripan, ukuran, dan karakteristik- nya, contohnya seperti pengelompokan tools, kunci L dengan sejenisnya yang mirip dan diberi kode nama serta kode lokasi kalau kode lokasi untuk alat itu disesuaikan dengan jurusannya seperti kode alat dengan kode TP itu alat milik teknik pemesinan dan TL itu kode alat untuk teknik las jadi sudah sesuai dan gam-pang dalam mencarinya sehingga siswa bisa bekerja dengan cepat dan tepat sesuai dengan standar oprasional prosedur.

Dengan diberi kode nama alat dan kode lokasi akan memudahkan dalam menemukan alat tersebut sesuai dengan konsep Saiton (Penataan) yaitu dapat menemukan alat dengan mudah dan menghilangkan proses pencarian alat yang membutuhkan waktu lama. Berikut ini hasil dokumentasi yang berupa gambar di bawah ini:

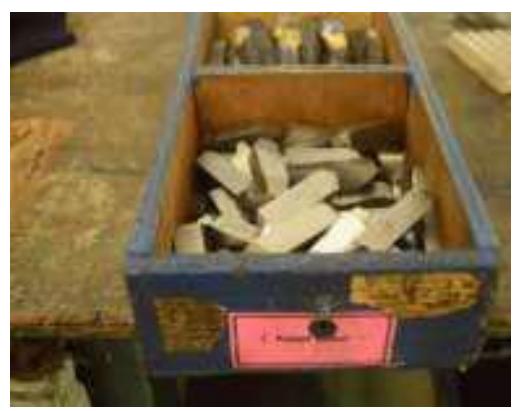

Gambar 2. Pelaksanaan Seiton Lokasi Penyimpanan Alat Sesuai dengan Nama Alat 


\section{b. Penataan Database}

Database di bengkel mesin otomotif fungsinya untuk mengarsip semua data peralatan/ mesin, benda kerja dan mencatat peralatan yang masuk dan keluar serta yang rusak dan tidak, sehingga semua jelas tercatat dalam bentuk format tertentu.

Dalam pengarsipan data base yang harus di perhatikan adalah:

1. Tetapkan dengan jelas tempat setiap arsip dan dokumen. Beri tanda pada setiap rak dan lemari untuk menunjukan apa yang disimpan disana. Percepat proses dengan membantu orang menemukan dengan segera informasi yang diperlukan.

2. Usahakan supaya setiap orang dapat memperoleh dan menggunakan informasi. Susunan arsip anda menurut seksi, bagian, divisi dan semacamnya. Jangan menciptakan keadaan dimana hanya seseorang saja yang mengetahui apa yang ada dan seseorang saja yang dapat menggunakan arsip.

3. Hanya simpan dokumen dan arsip yang benar-benar diperlukan. Tentukan standar dan kriteria untuk apa yang akan disimpan dan apa yang akan dibuang. Cegah sistem yang kompleks dan ruang yang tidak terpakai. Cegah pemborosan tempat dan proses yang tidak efisien.

Database bengkel sudah tertata dengan rapi tetapi masih berupa hardware akan mau dibuatkan software tapi masih tahap percobaan. Semua alat dan bahan yang ada di bengkel mesin otomotif semua tercatat bila ada barang masuk itu langsung di catat atau pun ada peralatan yang rusak itu semua sudah tercatat di database sebagai inventaris sekolah. Semua database bengkel yang berupa hardware semua tertata rapi didalam lemari khusus data base. Serta data base itu diberi kode nama contohnya data-base alat sendiri, bahan sendiri dan mesin sendiri. Berikut hasil dokumentasi yang berupa gambar:

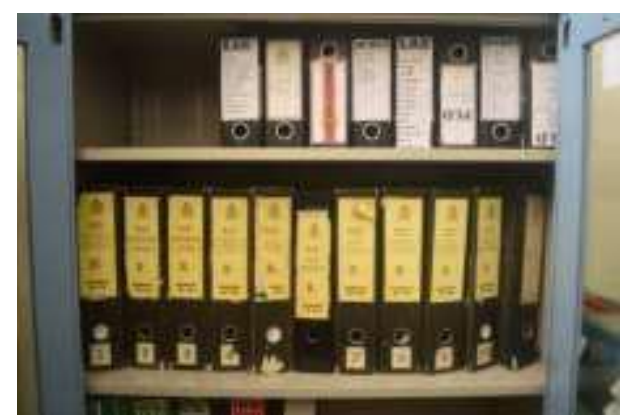

Gambar 3 Pelaksanaan Seiton Database Bengkel

\section{c. Pengelolaan Material Praktik}

Proses pengelolahan dari penerimaan material yang dibeli kemudian di data sebagai inventtaris dan ditaruh ditempat khusus untuk material dan dikelompokan sesuai dengan jurusannya seperti material untuk mesin sendiri dan otomotif sendiri. Dan juga sesuai dengan jenisnya kalau plat sendiri dan berbentuk pipa sendiri jadi semua material sudah ada tempat khusus dan dibedakan sesuai jurusan dan jenisnya. Berikut ini hasil dokumentasi yang berupa gambar di bawah ini.

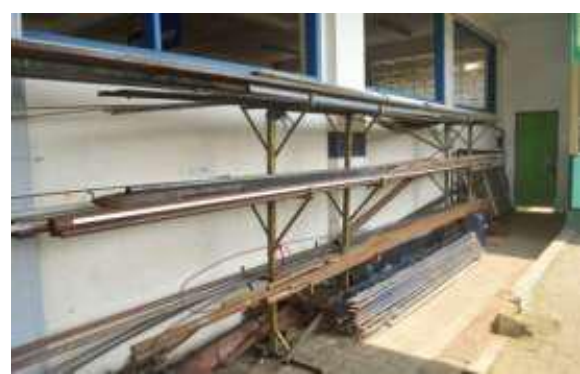

\section{Gambar 4 Pelaksanaan Seiton Tempat} Penyimpanan Material Praktik

\section{d. Pengelolaan Hasil Praktik Siswa}

Untuk pengelolaan hasil praktik mahasiswa mempunyai tempat khusus seperti box kayu dan diletakan di pojok bengkel dan setalah semua selesai. Berikut ini hasil dokumentasi yang berupa gambar: 


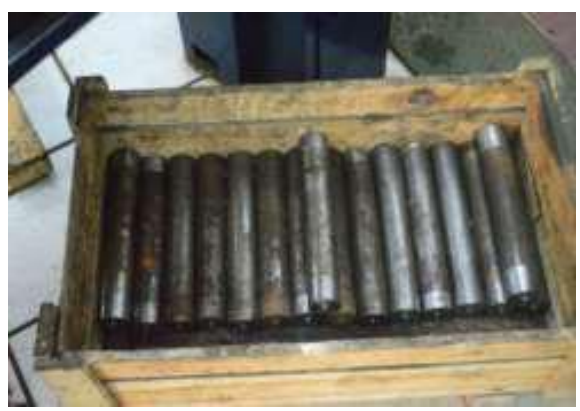

Gambar 5 Pelaksanaan Seiton Pada Bengkel

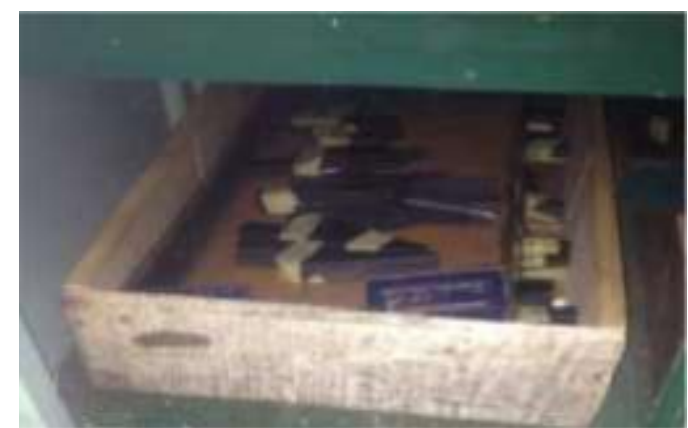

Gambar 6 Pelaksanaan Seiton Pada Bengkel Mesin

\section{Pelaksanaan Seiso}

Pelaksanaan Seiso di bagi menjadi dua yaitu bengkel yaitu:

\section{a. Pembersihan Bengkel}

Proses pembersihan di bengkel mesin itu ada yang bertanggung jawab masingmasing contohnya di dalam bengkel mesin itu yang bertanggungjawab atas kebersihan bengkel dan kerapian bengkel yang melibatkan mahasiswa.

Pembersihan bengkel itu melibatkan mahasiswa jadi dosen pembimbing hanya membagi mahasiswa menjadi beberapa kelompok untuk ditugaskan piket bengkel yang tugasnya yaitu membersihkan seluruh bengkel seperti lantainya disapu, membersihkan mesin dari gram-gram sisa praktek kemudian mengembalikan alat peraktek ke ruang laboran sehingga sehabis peraktek bengkel menjadi bersih seperti awal sebelum praktek. Untuk pembersihan di ruang laboran itu tanggung jawab dari laboran jadi pembersihannya setiap hari agar ruang laboran tertata rapi, bersih dan nyaman.

\section{b. Perawatan Mesin}

Proses perawatan mesin di bengkel mesin otomotif itu pasti dilakukan secara berkala agar meminimalisasi kekurangn atau pun kerusakan yang diakibatkan oleh kehausan sesuai dengan jadwal yang telah dibuat oleh kepala bengkel seperti perawatan mesin trainer kendaraan itu dua minggu sekali dan untuk alat ukur satu bulan sekali dan yang melakukan perawatan atau perbaikan itu tugas dari teknisi dan jadwal perawatan itu sudah dijadwalkan jadi teknisi tinggal lihat jadwal dan langsung

\section{Pelaksanaan Seiketsu}

Dalam seiketsu (pemantapan) di paparkan menjadi dua yaitu pemantapan di dalam bidangkontrol pemantapan SDM laboran, teknisi dan dosen pembimbing.

\section{a. Kontrol Visual}

Kontrol visual adalah suatu pemantapan bagi mahasiswa yang melakukan peraktik di bengkel agar bekerja sesuai dengan standar oprasional prosedur sehingga menghindar-kan dari kecelakaan kerja. fungsi kontrol visual sebagai berikut:

1. Peragaan untuk membantu orang mencegah membuat kesalahan

2. Waspada terhadap bahaya

3. Indikasi di mana barang harus diletakkan

4. Penanda peralatan

5. Peringatan untuk berhati-hati dan cara operasi

6. Peragaan pemeliharaan preventif

7. Intruksi

\section{Pelaksanaan Shitsuke}

Pembiasaan yang dilakakuan adalah jadi siswa selalu diingatkan mengenai K3 ketika sebelum dan sudah paktek di bengkel mesin otomotif, karena ketika diingatkan secara terus menurus mahasiswa akan terbiasa dalam memperhatikan keselamatanya sendiri dengan menggunakan alat pelindung diri ketika praktik.

Kebersihan bengkel menjadi yang utama di bengkel mesin otomotif. Kebersihan bengkel itu menjadi 
tanggujawab semua. Fungsi dosen disini mengarahkan agar mahasiswa setelah peraktik bertanggung jawab atas kebersihan bengkel serti peralatan yang ada dibengkel. Dosen selalu mengarahkan dan memberi teguran jika mahasiswa malas atau tidak mau membersihkan mesin yang habis di pergunakan. Dosen selalu mengarahkan untuk membersihkan bengkel sebelum pulang sehingga proses pembersihan bengkel oleh mahasiswa itu sudah menjadi kebiasaan dimana agar mahasiswa bertanggung jawab atas pekerjaannya. Beberapa hal yang menjadi kebiasaan yang perlu diubah dan dibiasakan dalam praktik pemesinan kepada setiap mahasiswa adalah adalah: (1) Tidak membiarkan tools berserakan di lantai. (2) Meletakkan alat pendukung yang penting bercampur dengan barang-barang yang tidakberguna. Hal ini harus dihilangkan dan prinsip meletakkan barang pada tempatnya harus dibiasakan. (3) Membiarkan mesin dalam keadaan kotor. Ini perlu diubah dan kita seharusnya membiasakan kegiatan membersihkan mesin sebelum dan sesudah mempergunakan.

Oleh karena itu dosen harus bisa mengatasi berbagai permasalahan yang dialami oleh mahasiswa yang berkaitan kebiasaan mahasiswa yang malas dalam membersihkan mesin setelah praktik. dosen harus bisa membiasakan mahasiswa bekerja dengan aman dan juga menjaga kebersihan bengkel. Proses pembiasaan dosen untuk mahasiswa adalah ketika sebelum praktik selalu ada briefing mengenai K3 agar mahasiswa bekerja dengan aman dan selalu menggunakan alat pelindung diri dan setelah praktik dosen membagi mahasiswa menjadi beberapa kelompok tugasnya adalah untuk membersihkan alat/mesin, bengkel dan mengembalikan alat ke laboran. Pembiasaan itu dilakukan setiap hari agar mahasiswa terbiasa bekerja aman dan bersih.

\section{KESIMPULAN DAN SARAN}

\section{Kesimpulan}

Pelaksanaan seiri di bengkel mesin otomotif sudah baik karena proses pemilihan barang yang tidak terpakai seperti sisa-sisa bahan praktikum itu di kumpulkan dan cara penanggulangan barang yang tidak terpakai sudah tepat setelah dikumpulkan.

Pelaksanaan seiton sudah baik karena setiap alat/mesin di letakan dengan rapi serta diberi kode nama dan kode lokasi, begitu juga penataan data base yang di susun sedemikian rupa di dalam lemari khusus database serta material praktik yang dikelompokan sesuai dengan jenisnya dan yang terakhir pengelolaan hasil praktik mahasiswa itu dengan menaruhnya di lemari khusus benda kerja.

Pelaksanaan seiso sudah baik karena proses pembersihan bengkel menjadi tanggung jawab mahasiswa dan dosen sehingga setelah selesai melakukan praktik mahasiswa dituntut untuk membersihkan bengkel, pearawatan mesin yang ada di bengkel mesin otomotif menjadi tanggung jawab laboran dan kepala bengkel, proses perawatan sudah ada jadwalnya yang telah dibuat oleh kepala bengkel.

Pelaksanaan seiketsu sudah baik karena di bengkel mesin dilengkapai dengan kontrol visual yang berupa poster-poster yang berfungsi mengi-ngatkan mahasiswa agar bekerja harus sesuai dengan procedural. Salah satu kegiatan seiket-su di bengkel mesin otomotif adalah mengirim laboran dan teknisi untuk mengikuti pelatihan guna meningkatkan kompetensinya sesuai dengan jurusannya.

Pelaksanaan shitsuke sudah baik karena dosen selalu memberikan briefing sebelum dan sesudah praktik mengenai keselamatan kerja dan bekerja sesuai prosedural sehingga mahasiswa dapat terbiasa bekerja aman dan nyaman. 


\section{Saran}

Adapun saran antara lain (1) Manajemen stratifikasi melalui penerapan strategi Label Merah (Red Tag) dalam upaya menciptakan tempat kerja yang Ringkas. (2) Menetapkan dan memberlakukan standar yang jelas dalam penyim-panan, sehingga semua peralatan yang ada mendapatkan tempat penyimpanan yang la-yak, rapi, dan aman. (3) Melakukan program pembersihan menyeluruh secara bersama-sama sampai ke tempat-tempat yang tersembunyi secara berkala dalam upaya menciptakan tempat kerja yang Resik. (4) Memperbarui peraga visual yang sudah usang dan membuat peraga visual yang belum ada misalnya penanda peletakan peralatan, denah penempatan peralatan, penggunaan kode warna, garis penanda wilayah, spanduk, dan lain-lain, serta memberikan penghargaan melalui kegiatan lomba kebersihan, pegawai teladan atau sejenisnya untuk memotivasi semua bagian yang terkait untuk terus menjunjung tinggi aturan dan tata tertib yang telah dibuat dalam upaya pemantapan (Rawat). (5) Mengajarkan setiap orang un-tuk menciptakan tempat kerja dengan kebia-saan dan perilaku yang baik, mempunyai komunikasi yang baik, kesadaran lingkung-an dan tanggung jawab yang tinggi melalui kegiatan workshop, seminar dan sebagainya dalam upaya membentuk tempat kerja yang berdisiplin (Rajin).

Huda, Miftahul Uzik. 2007. Studi Tentang Pengelolahan Laboratorium Pemesin-an SMK se-Kota Malang. Skripsi tidak diterbitkan. Malang: Universitas Negeri Malang.

Muhtiar. Y. 2007. Implementasi Metode 5S Pada Lean Six Sigma Dalam Proses Pembuatan Mur Baut Versing (Studi Kasus di CV. Desra Teknik Padang

Jurnal Teknik Industri Vol. 9, No. 1, Juni 2007: 63-74.

\section{DAFTAR PUSTAKA}

Hasibuan, S.P. 2009. Manajemen Dasar, Pengertian, Dan Masalah. Jakarta: Bumi Aksara.

Hadiguna, Rika \& Setiawan, Heri. 2008. Tata Letak Pabrik. Yogyakarta: Andi Offset.

Osada, T. 1996. Sikap Kerja 5S (Seiri, Seiton, Seiso, Seiketsu, Shitsuke). Jakarta: Ikrar Mandiri abadi.

Rimawan, E \& Sutowo, E. 2012. Analisa Penerapan $5 S+$ Safety Pada Area Warehouse di PT. Multifilling Mitra Indonesia. Jurnal Ilmiah Pasti Volume VI Edisi 1 - ISSN 2085-5869

Yoto. 2014. Manajemen Bengkel Teknik Mesin. Malang. Fakultas Universitas Negeri Malang. 